\title{
RELATIONSHIP OF OBESITY AND STRESS WITH HYPERTENSION EVENTS IN WOMEN IN NADGALO PADANG HEALTH CENTER
}

\author{
Fitria Alisa , Anes Yerden Trivina ${ }^{2}$ \\ ${ }^{1,2}$ STIKes Mercu Bakti Jaya Padang
}

Email : fitriaalisa1985@gmail.com

\begin{abstract}
Hypertension is a condition where an increase in blood pressure above normal. High prevalence of hypertension occurs in women. in Sumbar hypertension in women reaches 24\%, and in Puskesmas Nanggalo reaches $7.53 \%$. Factors of hypertension in women are obesity and stress. The purpose of this study was to determine the factors associated with the incidence of hypertension in women at the Nanggalo Padang Health Center. This research uses descriptive analytic cross sectional design. Data collection was conducted at Nanggalo Public Health Center in Padang with a sample of 57 people, with accidental sampling technique. Retrieval of data using primary data collected through questionnaires and weighing BMI and secondary data obtained from the documentation study at Padang Nanggalo Public Health Center. Data were processed with SPSS using univariate analysis of frequency distribution and bivariate chi- square test.The results of the study are known from 57 respondents $66.7 \%$ who suffer from hypertension, $78.4 \%$ respondents who are obese, $80 \%$ respondents are stressed Bivariate analysis showed that there was a relationship between. The relationship between obesity and hypertension $(\mathrm{p}=0.024 \leq 0.05)$. The relationship between stress and hypertension $(\mathrm{p}=0.030 \leq 0.05)$. From the results of this study the incidence of hypertension in women is related to the use obesity and stress. Suggestions for health workers to further improve counseling about healthy eating and exercise to prevent hypertension.
\end{abstract}

\section{Keywords: Hypertension, Obesity and Stress}

\section{PENDAHULUAN}

Perempuan sekarang lebih maju dari pada perempuan zaman dulu. Hal ini disebabkan karena perkembangan zaman yang semakin maju, sehingga kesibukan pada perempuan semakin bertambah dan bertanggung jawab dalam segala aktivitasnya. Dengan begitu masalah penyakit pun sangat beresiko terjadi pada perempuan. Penyakit yang sering terjadi pada perempuan yaitu penyakit kardiovaskuler, infeksi, diabetes mellitus, dan lain-lain. Penyakit kardiovaskuler merupakan penyebab utama kematian perempuan dan laki-laki. Faktor resiko yang terkait 
dengan penyakit kardiovaskuler pada perempuan adalah hipertensi, diabetes mellitus, merokok, obesitas, dan ketidak aktifan fisik (Kevin A, dkk. 2014).

Hipertensi adalah penyebab utama mortalitas dan morbiditas di Indonesia, hipertensi terjadi pada seseorang yang memiliki tekanan darah sistolik $\geq 140 \mathrm{mmHg}$ dan atau tekanan darah $\geq 90 \mathrm{mmHg}$ pada pemeriksaan yang berulang. Hipertensi adalah keadaan dimana terjadinya peningkatan tekanan darah diatas normal dan terus berlanjut pada beberapa kali pemeriksaan tekanan darah yang disebabkan oleh beberapa faktor yang tidak berjalan semestinya dalam mempertahankan tekanan darah secara normal (Wijaya \& Putri, 2014).

Menurut Organisasi Kesehatan Dunia (WHO, World Health Organization) hipertensi merupakan faktor resiko penyakit kardiovaskuler. WHO mencatat pada tahun 2015 kasus hipertensi didapatkan 1,13 miliar orang di dunia menderita hipertensi, artinya 1 dari 3 orang di dunia terdiagnosis menderita hipertensi, di Amerika sekitar 250 juta orang penderita hipertensi dimana setiap tahun 1,6 juta kematian dan penderitanya lebih banyak perempuan (30\%) di bandingkan dengan laki-laki (29\%). Diseluruh dunia sebanyak $40 \%$ dari jumlah orang dewasa berusia 25 tahun keatas telah di diagnosa hipertensi sebanyak $80 \%$ kenaikan hipertensi terjadi terutama di negara-negara berkembang (Triyanto, 2014).

Prevalensi hipertensi di Indonesia berdasarkan pengukuran penduduk umur $\geq 18$ tahun yaitu pada tahun 2013 sebanyak 31,7\% dan meningkat pada tahun 2018 sebanyak 34,1\% dari jumlah penduduk (Riskesdas, 2018). Berdasarkan laporan dari seluruh kabupaten kota pada tahun 2017, penyakit hipertensi menduduki peringkat ke tiga dari sepuluh penyakit terbanyak di provinsi Sumatera Barat sebanyak 13,8\%. Jumlah penderita hipertensi menurut jenis kelamin pada lakilaki sebanyak 60,166 (21,7\%) dan pada perempuan sebanyak 83, 985 (24,0\%) (Dinkes. Sumbar, 2017).

Berdasarkan laporan Dinas Kesehatan Kota Padang, tahun 2017 menyebutkan bahwa penyakit hipertensi terletak pada urutan ke dua dari sepuluh penyakit. Hipertensi biasanya di derita oleh orang dewasa, namun sekarang pada usia muda (> 18 Tahun ) sudah mengalami penyakit hipertensi. Penduduk usia >18 tahun sebanyak 206.417 jiwa dilakukan pengukuran tekanan 
darah, hasilnya terdapat 9.587 orang terdiagnosa penyakit hipertensi atau sebesar 4,64\%. Penyakit hipertensi banyak di derita oleh perempuan yaitu sebanyak 5.909 orang sedangkan pada laki- laki sebanyak 3.678 orang. Pada Puskesmas Nanggalo jumlah terdiagnosa hipertensi pada perempuan sebanyak 332 orang (7,53\%) sedangkan pada laki-laki sebanyak 225 orang $(5,18 \%)$ (Profil Kesehatan Kota Padang Tahun 2017). Ditinjau dari perbandingan antara laki-laki dan perempuan, ternyata perempuan lebih banyak menderita hipertensi. Salah satu faktor pendorong hipertensi pada perempuan adalah obesitas/gemuk. Fakta bahwa perempuan cenderung mengalami obesitas saat mereka menua. Usia semakin bertambah sendiri juga menjadi faktor pendukung terjadinya hipertensi. Sifat perempuan yang suka mengedepankan kepentingan anak, suami dan keluarga, membuat perempuan terkadang memilih untuk menunda kepentingan dirinya untuk mendapatkan pengobatan dan perawatan sehingga dapat menimbulkan stress.

Obesitas dapat memicu terjadinya hipertensi akibat terganggunya aliran darah. Hal tersebut terjadi karena mengalami peningkatan kadar lemak dalam darah (hiperlipidemia) sehingga berpotensi menimbulkan penyempitan pembuluh darah (ateroklerosis) (Sari, 2017). Berdasarkan hasil penelitian dari Simamora, dkk (2019) pengaruh kejadian hipertensi terjadi sebanyak43 kasus $(63,2 \%)$. Pada faktor stress merupakan salah satu penyebab terjadinya hipertensi karena salah satunya,perempuan zaman sekarang sibuk mengutamakan pekerjaan dan kesuksesan. Kesibukan dan kerja keras serta untuk mencapai tujuan yang berat dapat mengakibatkan timbulnya stress. Tekanan darah akan meningkat saat mengalami perasaan tertekan (Jannah, dkk, 2017). Berdasarkan hasil penelitian Ahmad (2017) perempuan lebih tinggi jumlah stress dibanding laki-laki. Pada penelitian tersebut sebanyak $73 \%$ sedangkan pada laki-laki $27 \%$.

Berdasarkan dari hasil wawancara dan kuesioner yang dilakukan oleh peneliti dari 10 pasien hipertensi pada perempuan yang berkunjung di Puskesmas Nanggalo Padang, didapatkan keterangan bahwa 3 orang mengalami berat badan berlebih (Obesitas), dan 3 orang mengalami stress berat. Berdasarkan fenomena di atas maka peneliti tertarik untuk melihat hubungan obesitas dan stress dengan kejadian hipertensi pada perempuan di wilayah kerja puskesmas 
nanggalo padang.

\section{METODE}

Penelitian ini merupakan penelitian deskriptif analitik dengan pendekatan desain penelitian cross sectional dengan populasi sampel seluruh pasien perempuan yang berkunjung ke Puskesmas Nanggalo dengan jumlah 57 orang responden. Teknik pengambilan sampel (sampling) dalam penelitian ini menggunakan metoda accidental sampling. Pengumpulan data dilakukan dengan wawancara terpimpin dimana pengolahan data bivariat menggunakan ChiSquare.

\section{HASIL}

\section{A. Analisa Univariat}

Tabel 1. Distribusi Frekuensi Responden Berdasarkan Kejadian Hipertensi di Puskesmas Nanggalo Padang

\begin{tabular}{c|c|l|c}
\hline No & Kejadian Hipertensi & $\boldsymbol{f}$ & Persentase \\
\hline $\mathbf{1}$ & Hipertensi & 38 & 66,7 \\
$\mathbf{2}$ & Tidak Hipertensi & 19 & 33,3 \\
\hline & Jumlah & $\mathbf{5 7}$ & $\mathbf{1 0 0 , 0}$ \\
\hline
\end{tabular}

Tabel 1 diatas dapat dilihat bahwa dari 57 orang responden terdapat lebih dari separoh $(66,7 \%)$ responden menderita hipertensi di Puskesmas Nanggalo Padang.

Tabel 2. Distribusi frekuensi responden berdasarkan Obesitas di Puskesmas Nanggalo Padang

\begin{tabular}{|c|c|c|c|}
\hline No & Obesitas & $f$ & Persentase \\
\hline 1 & Obesitas & 37 & 64,9 \\
\hline 2 & Tidak obesitas & 20 & 35,1 \\
\hline & Jumlah & 57 & 100 \\
\hline
\end{tabular}

Tabel 2 diatas dapat dilihat bahwa dari 57 orang responden terdapat lebih dari separoh (64,9 \%) responden mengalami obesitas di Puskesmas Nanggalo Padang.

Tabel 3. Distribusi Frekuensi Responden Berdasarkan Stress di Puskesmas Nanggalo Padang

\begin{tabular}{cclc}
\hline No & Stress & $\boldsymbol{F}$ & Persentase \\
\hline $\mathbf{1}$ & Stress berat & 11 & 19,3 \\
$\mathbf{2}$ & Stress sedang & 25 & 43,9 \\
$\mathbf{3}$ & Stress ringan & 13 & 22,8 \\
\hline \hline
\end{tabular}

Jurnal Vokasi Keperawatan (JVK) Volume 3 No 2 Bulan Desember Tahun 2020

Program Study of Nursing Universitas Bengkulu

http://ejournal.unib.ac.id/index.php/JurnalVokasiKeperawatan 


\begin{tabular}{cccc}
$\mathbf{4}$ & Normal & 8 & 14,0 \\
\hline & Jumlah & $\mathbf{5 7}$ & $\mathbf{1 0 0 , 0}$ \\
\hline
\end{tabular}

Tabel 3 diatas dapat dilihat bahwa dari 57 orang responden terdapat lebih dari separoh $(43,9 \%)$ responden mengalami stress sedang di Puskesmas Nanggalo Padang.

\section{B. Analisa Bivariat}

Tabel 4. Hubungan Obesitas dengan Kejadian Hipertensi

\begin{tabular}{|c|c|c|c|c|c|c|c|c|}
\hline \multirow[t]{3}{*}{ No } & \multirow[t]{3}{*}{ Obesitas } & \multicolumn{4}{|c|}{ Kejadian } & \multirow[t]{3}{*}{ Total } & \multirow[t]{3}{*}{$\%$} & \multirow{3}{*}{$\begin{array}{c}p \\
\text { value }\end{array}$} \\
\hline & & \multicolumn{2}{|c|}{$\begin{array}{l}\text { Tidak } \\
\text { Hipertensi }\end{array}$} & \multicolumn{2}{|c|}{ Hipertensi } & & & \\
\hline & & $f$ & $\%$ & $f$ & $\%$ & & & \\
\hline 1 & Obesitas & 8 & 21,6 & 29 & 78,4 & 37 & 100 & 0,024 \\
\hline \multirow[t]{2}{*}{2} & Tidak Obesitas & 11 & 55 & 9 & 45 & 20 & 100 & \\
\hline & Jumlah & 19 & 33,3 & 24 & 66,7 & 43 & 100 & \\
\hline
\end{tabular}

Tabel 4 diatas dapat dilihat bahwa dilihat bahwa dari 37 perempuan yang obesitas lebih banyak dari separuh (78.4\%) responden yang mengalami hipertensi, dibandingkan dengan 20 perempuan yaitu lebih dari separuh (55\%) responden tidak menderita hipertensi. Hasil uji statistic menggunakan uji chi square didapatkan nilai $p=0,024(p<0,05)$ artinya terdapat hubungan obesitas dengan kejadian hipertensi di Puskesmas Nanggalo Padang.

Tabel 5. Hubungan Stres Dengan Kejadian Hipertensi

\begin{tabular}{|c|c|c|c|c|c|c|c|c|}
\hline \multirow[t]{3}{*}{ No } & \multirow{3}{*}{ Stres } & \multicolumn{4}{|c|}{ Kejadian } & \multirow[t]{3}{*}{ Total } & \multirow[t]{3}{*}{$\%$} & \multirow{3}{*}{$\begin{array}{c}p \\
\text { value }\end{array}$} \\
\hline & & \multicolumn{2}{|c|}{ Tidak Hipertensi } & \multicolumn{2}{|c|}{ Hipertensi } & & & \\
\hline & & $f$ & $\%$ & $f$ & $\%$ & & & \\
\hline 1 & Stres berat & 5 & 45,5 & 6 & 54,4 & 11 & 100 & $\mathbf{0 , 0 3 0}$ \\
\hline 2 & Stres sedang & 5 & 20,0 & 20 & 80 & 25 & 100 & \\
\hline 3 & Stres ringan & 5 & 38,5 & 8 & 61,5 & 13 & 100 & \\
\hline 4 & Normal & 7 & 87,5 & 1 & 12,5 & 8 & 100 & \\
\hline & umlah & 22 & 38,6 & 24 & 20 & 43 & 100 & \\
\hline
\end{tabular}

Tabel 5 diatas dapat dilihat bahwa dari 25 perempuan stress sedang yaitu lebih banyak dari separuh (80\%) responden yang menderita hipertensi dibandingkan dengan (20\%) responden yang tidak menderita hipertensi. Hasil uji statistic menggunakan uji chi square didapatkan nilai $p=0,030(p<0,05)$ artinya terdapat hubungan stres dengan kejadian hipertensi di Puskesmas Nanggalo Padang.

Jurnal Vokasi Keperawatan (JVK) Volume 3 No 2 Bulan Desember Tahun 2020

Program Study of Nursing Universitas Bengkulu

http://ejournal.unib.ac.id/index.php/JurnalVokasiKeperawatan 


\section{PEMBAHASAN}

\section{Analisa Univariat}

\section{A. Kejadian Hipertensi}

Berdasarkan hasil penelitian bahwa dari 57 perempuan didapatkan lebih dari separuh (66.7\%) responden yang menderita hipertensi di Puskesmas Nanggalo Padang. Banyaknya perempuan yang menderita hipertensi hampir sama dengan penelitian yang dilakukan oleh Nuarima (2016) tentang faktor resiko hipertensi pada masyarakat di desa Kabongan Kidul, Kabupaten Rembang. Ditemukan bahwa hipertensi lebih banyak terjadi pada perempuan yaitu lebih dari separuh $(52,8 \%)$ yang menderita hipertensi. Persamaan dari penelitian ini terdapat pada jumlah sampel hampir sama yaitu 69 sampel pada perempuan. Hasil uji statistik (chi square) diperoleh nila $p=0.030(p \leq 0.05)$, maka dapat disimpulkan bahwa terdapat hubungan stress dengan kejadian hipertensi. Penentuan ini berbeda dengan penelitian yang dilakukan oleh Novitaningtyas, (2015) tentang hubungan karakteristik (umur, jenis kelamin, tingkat pendidikan) dan aktifitas fisik dengan tekanan darah di Kelurahan Makam Haji Kecamatan Kartasura Kabupaten Sukoharjo. Ditemukan bahwa terdapat kurang dari separuh $(43,7 \%)$ perempuan yang menderita hipertensi. Perbedaan penelitian ini dengan yang dilakukan oleh Novitanoingtyas adalah pada metode yang digunakan yaitu uji Fisher Exact dengan jumlah sampel yaitu 40 responden.

Menurut teori hipertensi pada perempuan mengalami peningkatan setelah masuk pada usia monopouse. Hal tersebut karena disebabkan oleh adanya perubahan hormonal yang dialami perempuan monopouse (Sari, 2017). Usia semakin bertambah sendiri juga menjadi faktor pendukung terjadinya hipertensi (Ulfah,2015). Hipertensi merupakan peningkatan tekanan darah dalam arteri.Secara umum, hipertensi merupakan suatu keadaan tanpa gejala, dimana tekanan yang abnormal tinggi di dalam arteri (Triyanto, 2014).Pada hipertensi sistolik mencapai $140 \mathrm{mmHg}$ atau lebih, tetapi tekanan darah diastolik kurang dari $90 \mathrm{mmHg}$ (Triyanto, 2014).Hipertensi ada terbagi dua yaitu hipertensi esensial (primer) dan hipertensi sekunder. Pada hipertensi primer penyebabnya belum diketahui, akan tetapi ada beberapa faktor yang 
mempengaruhi hipertensi primer tersebut yaitu faktor genetik, stress, psikologis, faktor lingkungan, dan diet (mengkonsumsi garam dan berkurangnya asupan kalium dan kalsium). Sedangkan pada hipertensi sekunder yaitu lebih mudah dikendalikan dengan obatobatan, penyebabnya sudah diketahui diantaranya merupakan kelainan ginjal seperti obesitas, retensi insulin, hipertiroidisme dan pemakaian obat-obatan seperti kontrasepsi oral dan kortikosteroid (Abdul, 2017).

Menurut asumsi peneliti hipertensi pada perempuan disebabkan karena keturunan dari keluarga, jika salah satu keluarga menderita hipertensi kemungkinan besar responden juga akan mengalami hipertensi. Semakin bertambahnya usia, pada saat usia 45 tahun sampai > 55 tahun keelastisitasan pembuluh darah menurun dan terjadi peningkatan retensi pembuluh darah perifer. Pola makan yang tidak baik seperti mengkonsumsi garam berlebihan serta pengaruh stres pada perempuan dalam segi mengurus suami, anak dan pekerjaan di rumah sehingga lalai untuk melakukan pemeriksaan kesehatan. Dibuktikan dalam kuisoner penelitian pada perempuan yang berkunjung di Puskesmas Nanggalo Padang 54.4\% yang bekerja sebagai ibu rumah tangga dan $66.7 \%$ responden.

\section{B. Obesitas}

Berdasarkan hasil penelitian bahwa dari 57 perempuan didapatkan lebih separuh (64.9\%) responden yang mengalami obesitas di Puskesmas Nanggalo Padang. Banyaknya perempuan yang obesitas itu setara dengan penelitian yang dilakukan Nieky (2014) yang menyatakan bahwa lebih dari separuh $(61,9 \%)$ dari 42 responden mengalami obesitas. Hasil penelitian ini hampir sama dengan hasil penelitian Haryuti, dkk (2017) tentang gambaran tekanan darah dan indikator obesitas wanita usia subur di Wilyah Kerja Puskesmas Tlogosari Wetan Kota Semarang yang menunjukkan bahwa sebagian besar responden memiliki status obesitas lebih dari separuh (58\%). Hasil ini sama dengan penelitian yang dilakukan oleh Mawardias (2014) tentang hubungan indeks massa tubuh dan lingkar pinggang dengantekanan darah pada wanita dewasa di Dusun Kalibang Desa Wono Kerto Kecamatan Wonogiri Propinsi Jawa Tengah menyebutkan bahwa proporsi responden paling banyak pada responden yang mengalami obesitas yaitu lebih dari separuh (53.7\%). Persamaan penelitian ini terletak pada sampel yang digunakan adalah 
perempuan. Menurut teori obesitas adalah suatu keadaan penumpukan lemak berlebih pada dalam tubuh.Obesitas dapat memicu terjadinya hipertensi akibat terganggunya aliran darah. Dalam hal ini, orang dengan obesitas biasanya mengalami peningkatan kadar lemak dalam darah (hiperlipidemia) sehingga berpotensi menimbulkan penyempitan pembuluh darah (ateroklerosis). Penyempitan terjadi akibat penumpukan plak ateromosa yang berasal dari lemak. Penyempitan tersebut memicu jantung untuk bekerja meompa darah lebih kuat agar kebutuhan oksigen dan zat lain yang dibutuhkan oleh tubuh dapat terpenuhi. Hal inilah yang menyebabkan tekanan darah meningkat. Hipertensi juga dapat dipicu oleh faktor lain yang juga berkaitan dengan obesitas antara lain hiperlipidemia, aterosklerosis, konsumsi lemak berlebih, kurangnya konsumsi serat dan kurangnya aktifitas fisik (Ulfah, 2015).

Menurut analisa peneliti obesitas terjadi akibat pola makan yang tidak baik seperti mengkonsumsi garam berlebihan, daging berlebihan, mengkonsumsi makanan yang berlemak, sehinggaterjadi timbunan kolestrol dalam pembuluh darah, penumpukan lemak menyebabkan arteri menyempit sehingga perlu tekanan lebih besar untuk mengalirkan darah keseluruh tubuh. Dibuktikan setelah melakukan penelitian pada perempuan yang berkunjung di Puskesmas Nanggalo Padang ditemukan 37 perempuan yang mengalami obesitas.

\section{Stres}

Berdasarkan hasil penelitian dapat dilihat bahwa dari 57 perempuan didapatkan kurang dari separuh (43.9\%) yang mengalami stress sedang pada perempuan di Puskesmas Nanggalo Padang. Hasil penelitian ini tidak sama dengan penelitian yang dilakukan oleh Azmi (2014) tentang faktor-faktor yang berhubungan dengan kejadian hipertensi pada masyarakat di Wilayah Kerja Puskesmas Rumbai Pesisir. Hasil penelitian menunjukkan bahwa sebagian besar responden adalah perempuan dari 65 responden yang mengalami stress sedang yaitu lebih banyak dari separuh (76.9\%). Perbedaan penelitian ini dengan penelitian yang dilakukan oleh Lailatun Azmi adalah pada sampel penelitian sebanyak 65 responden dan desain penelitian analitik dengan pendekatan case control study. Menurut teori pada faktor lingkungan dapat menyebabkan terjadinya kejadian hipetensi seperti seseorang yang dalam keadaan stres sangat 
berpengaruh terhadap timbulnya hipertensi. Hubungan antara stress dengan hipertensi, diduga melalui aktivasi saraf simpatis (saraf yang bekerja pada saat kita beraktivitas). Apabila stress berkepanjangan, dapat mengakibatkan hipertensi menetap cukup tinggi(Endang, 2014).Black dan Haws (2011) mengatakan bahwa stress meningkatkan resistensi pembuluh darah perifer dan menstimulasi aktivitas system saraf simpatis yang berakhir pada hipertensi. Apabila stress terjadi hormone epinefrin atau adrenalin terlepas. Aktifitas hormon ini meningkatkan tekanan darah secara berkala. Jika stress berkepanjangan, peningkatan tekanan darah menjadi permanen. Hasil ini dibuktikan pada kuisoner penelitian pekerjaan ibu rumah tangga didapatkan lebih sedangkan yang PNS sedikit dari separuh (10.5\%). Stress akan meningkatkan resistensi pembuluh darah perifer dan curah jantung sehingga akan merangsang saraf simpatetik dan sangat berhubungan dengan pekerjaan, kelas sosial, ekonomi dan karakteristik personal.

\section{Analisa Bivariat}

\section{A. Hubungan Obesitas Dengan Kejadian Hipertensi}

Berdasarkan hasil penelitian didapatkan bahwa kejadian hipertensi pada perempuan banyak terjadi pada responden yang obesitas yaitu lebih banyak dari separuh (78.4\%) dibandingkan pada responden yang tidak mengalami obesitas yaitu lebih dari separuh (55\%). Hasil uji statistik (chi-square) diperoleh nilai $p=0.024 \leq 0.05$, maka dapat disimpulkan bahwa terdapat hubungan Obesitas dengan kejadian hipertensi pada perempuan di Puskesmas Nanggalo Padang. Hasil penelitian ini hampir sama dengan penelitian Dien, dkk (2014) tentang Hubungan Indeks Massa Tubuh dengan tekanan darah pada penderita hipertensi di Poli Klinik Hipertensi dan Nefrologi Blu RSUP Prof. Dr R.D Kandou Manado. Didapatkan hasil bahwa lebih dari separuh (61.9\%) yang mengalami obesitas dengan kejadian hipertensi sehingga $p=$ $0.006(\leq 0.05)$ yang artinya terdapat hubungan bermakna. Penelitian ini hampir sama dengan penelitian Dien, dkk dengan jumlah sampel perempuan sebanyak 55 responden. Obesitas merupakan salah satu dari faktor resiko hipertensi. Seseorang yang mengalami obesitas akan membutuhkan lebih banyak darah untuk menyuplai oksigen dan makanan kejaringan tubuhnya, sehingga volume darah yang beredar melalui pembuluh darah meningkat, curah jantung akan meningkat dan akhirnya tekanan darah ikut meningkat. Selain obesitas meningkatkan kadar insulin dalam darah.

\footnotetext{
Jurnal Vokasi Keperawatan (JVK) Volume 3 No 2 Bulan Desember Tahun 2020

Program Study of Nursing Universitas Bengkulu

http://ejournal.unib.ac.id/index.php/JurnalVokasiKeperawatan
} 
Peningkatan insulin ini menyebabkan retensi natrium pada ginjal sehingga tekanan darah ikut naik (Morrison, 2011).Seringnya mengkonsumsi makanan dan minuman yang mengandung lemak berlebih, kurang berolahraga, dapat mengakibatkan obesitas atau berat badan yang berlebih dari normal. Timbunan kolesterol dalam pembuluh darah dapat terjadi akibat kandungan lemak yang berlebih dalam pembuluh darah sehingga pembuluh darah menyempit, lalu tekanan darah meningkat sehingga terjadi hipertensi. Orang yang menderita obesitas akan memiliki kemungkinan terjadinya penyakit hipertensi lebih besar dibanding yang bertubuh ideal. Dalam hal ini, orang dengan obesitas biasanya mengalami peningkatan kadar lemak dalam darah (hiperlipidemia) sehingga berpotensi menimbulkan penyempitan pembuluh darah (ateroklerosis). Penyempitan terjadi akibat penumpukan plak ateromosa yang berasal dari lemak.Penyempitan tersebut memicu jantung untuk bekerja meompa darah lebih kuat agar kebutuhan oksigen dan zat lain yang dibutuhkan oleh tubuh dapat terpenuhi. Hal inilah yang menyebabkan tekanan darah meningkat (Ulfah, 2015). Menurut analisa peneliti bahwa adanya hubungan obesitas dengan kejadian hipertensi pada perempuan,disebabkan salah satunya adalah pola makan yang tidak teratur seperti mengkonsumsi garam berlebih, mengkonsumsi dagaing dengan kadar lemak tinggi, gorengan serta berpengaruh pada penggunaan kontrasepsi hormonal yang mengandung komponen esterogen yang dapat memberikan efek pertambahan berat badan akibat restensi cairan, dan penyempitan terjadi akibat penumpukan plak ateromosa yang berasal dari lemak. Penyempitan tersebut memicu jantung untuk bekerja meompa darah lebih kuat. Hal ini terbukti dari hasil kuisoner dimana lebih banyak dari separuh (74.4\%) responden yang mengalami obesitas dengan kejadian hipertensi.

\section{B. Hubungan Stres dengan Kejadian Hipertensi}

Berdasarkan hasil penelitian didapatkan bahwa kejadian hipertensi pada perempuan banyak terjadi pada responden yang mengalami stres sedang yaitu lebih banyak dari separuh (80\%) dibandingkan dengan responden tidak mengalami hipertensi yaitu sedikit dari separuh (20\%). Hasil uji statistik (chi-square) diperoleh nilai $p=0.030 \leq 0.05$, maka dapat disimpulkan bahwa terdapat hubungan dengan kejadian hipertensi pada perempuan di Puskesmas Nanggalo Padang. Hasil penelitian inihampirsama dengan penelitian yang dilakukan oleh Fajar Hermawan (2014) 
tentang hubungan tingkat stress dengan kejadian hipertensi pada Dewasa Akhir di Gamping Sleman Yogyakarta. Didapatkan hasil dari 30 responden yang mengalami stress sedang yaitu lebih banyak dari separuh (83.3\%) sehingga dapat dilihat hasil analisa data dengan menggunakan korelasi spearman rank didapatkan hasil nilai $p$ hitung 0.409 dan $p=0.013$ $(\leq 0.05)$ yang artinya terdapat hubungan bermakna. Persamaan penelitian ini dengan penelitian yang dilakukan oleh Fajar Hermawan adalah instrument penelitian dengan kuisoner.

Menurut teori stress adalah tanggapan atau reaksi terhadap berbagai tuntutan atau beban atasnya yang bersifat nonspesifik namun, disamping itu stres dapat juga merupakan faktor pencetus, penyebab sekaligus akibat dari suatu ngangguan atau penyakit. Faktor-faktor psikososial cukup mempunyai arti bagi terjadinya stres pada diri seseorang. Stres dalam kehidupan adalah suatu hal yang tidak dapat dihindari (Yosep \& Sutini, 2014). Penyebab stres atau disebut stressor dapat berubah-ubah sejalan dengan perkembangan manusia tetapi kondisi stres dapat juga setiap saat sepanjang kehidupan. Sumber-sumber stres yaitu dari dalam diri, dalam keluarga dan dalam komunitasstres sebagai stimulus, stres sebgai respon dan stres sebagai interaksi antara individu dan lingkungan (Kenia, 2013). Stres merupakan ketidak mampuan mengatasi ancaman yang dihadapi oleh mental, fisik, emosional dan spiritual manusia, pada suatu saat yang dapat mempengaruhi kesehatan fisik manusia tersebut. Stres akan meningkatkan retensi pembuluh darah perifer dan curah jantung sehingga akan merangsang aktifitas saraf simpatik. Adapun stres ini dapat berhubungan dengan pekerjaan, kelas sosial, ekonomi dan karakteristik personal (Ulfah, 2015). Menurut analisa peneliti adanya hubungan stres dengan kejadian hipertensi pada perempuan sangat berpengaruh terhadap lingkungan dalam keluarga maupun dalam komunitas dalam pekerjaan dan perekonomian. Disebabkan dalam pembagian waktu dalam melakukan aktifitas antara mengurus suami, anak dan pekerjaan serta komunitas yang diikuti sangat mempengaruhi terjadinya stres pada ibu rumah tangga. Hal ini dibuktikan pada pengisian kuisoner yang dilakukan lebih dari separuh perempuan yang bekerja sebagai ibu rumah tangga yaitu sebanyak (54.4\%) dan diberi pernyataan bahwa ibu rumah tangga lebih mementingkan kebutuhan suami dan anak serta pekerjaan dibanding dengan kesehatannya sendiri.

\footnotetext{
Jurnal Vokasi Keperawatan (JVK) Volume 3 No 2 Bulan Desember Tahun 2020

Program Study of Nursing Universitas Bengkulu

http://ejournal.unib.ac.id/index.php/JurnalVokasiKeperawatan
} 


\section{SIMPULAN DAN SARAN}

\section{SIMPULAN}

Berdasarkan hasil penelitian diatas dapat disimpulkan bahwa untuk hasil univariat didapatkan lebih dari separuh (66.7\%) perempuan yang menderita hipertensi pada perempuan di Puskesmas Nanggalo Padang, dan lebih dari separuh (64.9\%) perempuan yang mengalami obesitas pada perempuan di Puskesmas Nanggalo Padang serta hampir dari separuh (43.9\%) perempuan yang mengalami stres sedang pada perempuan di Puskesmas Nanggalo Padang. Berdasarkan hasil bivariat untuk hubungan obesitas dan kejadian hipertensi didapatkan adanya hubungan antara obesitas dengan kejadian hipertensi pada perempuan di Puskesmas Nanggalo Padang dan untuk hubungan stres dan kejadian hipertensi didapatkan adanya hubungan antara stress dengan kejadian hipertensi pada perempuan di Puskesmas Nanggalo Padang.

\section{SARAN}

Saran dalam penelitian ini diharapkan petugas pelayanan kesehatan untuk lebih meningkatkan penyuluhan dan pemantauan tentang obesitas dan stres untuk mencegah hipertensi serta dapat dijadikan sebagai data dasar bagi peneliti selanjutnya untuk melihat faktor-faktor lain yang berhubungan dengan kejadian hipertensi pada perempuan

\section{DAFTAR RUJUKAN}

Aspiani, R. Y. (2014). Buku Ajar Asuhan Keperawatan Klien Gangguan Kardiovaskuler.Jakarta : EGC.

Azmi,.L.(2014). Faktor- Faktor Yang Berhubungan Dengan Kejadian Hipertensi Di Wilayah Kerja Puskesmas Rumbai Pesisir.Jurnal Keperawatan (E-Journal), 5 (1), 235242.

Bustam, M. N. (2015). Manajemen Pengendalian Penyakit Tidak Menular. Jakarta: Rineka Cipta.

Bybee, K. A., \& L, S. (2014). Penyakit Kardiovaskuler pada Wanita. Jakarta : Erlangga

Dinas Kesehatan Kota Padang. (2017). Profil Kesehatan Kota Padang, (45)

\footnotetext{
Jurnal Vokasi Keperawatan (JVK) Volume 3 No 2 Bulan Desember Tahun 2020

Program Study of Nursing Universitas Bengkulu

http://ejournal.unib.ac.id/index.php/JurnalVokasiKeperawatan
} 
Guyton \& Hull. (2011). Buku Ajar Fisiologi Kedokteran.Singapura : Elsevier.

Kolibu, F., \& Kalesaran, A. (2018). Faktor-Faktor Yang Berhubungan Dengan Terjadinya Hipertensi Pada Masyarakat Desa Tempok Selatan Kecamatan Tompaso Kabupaten Minahasa. KESMAS, 7(1).

Nieky.S . (2014). Faktor-faktor yang Berhubungan Dengan Kejadian Hipertensi Pada Wanita Usia Subur Di Puskesmas Umbulharjo I Yogyakarta Tahun 2014. Jurnal Kesehatan Masyarakat (Journal ofPublic Health), 4(2), 94-102. doi.org/10.12928/kesmas.v4i2.1027

Nursalam. (2013). Penelitian Ilmu Keperawatan : Pendekatan Praktis. Jakarta : Salemba Medika Notoadmojo.(2012). Metodologi Penelitian Kesehatan.Jakarta : Rinkes Cipta

Rizky, E. (2017). Hubungan Antara Stres dengan Kejadian Hipertensi pada Dewasa Awal di Dusun Bendo Desa Trimurti Srandakan Bantul Yogyakarta. Retrieved from http://elibrary.almaata.ac.id/717/1/skripsi gabung.pdf Diakses pada tanggal 28 Maret 2019

Riskesdas. (2018). Hasil Utama Riskesdas2018.Kementrian Kesehatan Republik Indonesia, 1-100. doi.org/1 Desember 2013

Sari, Y. N. I. (2017). Berdamai dengan Hipertensi.Jakarta : Bumi Medika.

Supardi, S. (2013). Buku Ajar Metode Riset Keperawatan. Jakarta : Trans Info Media.

Triyanto, E. (2014). Pelayanan Keperawatan Penderita Hipertensi Terpadu. Yogyakarta: Graha Ilmu.

Wade, Calsrson. (2016). Mengatasi Hipertensi. Bandung: Nuansa Cendekia

WHO. (2013). A global brief on Hyper tension World Health Day 2015.World Health Organization, $1-40$ 